\title{
La estrategia competitiva que adopta la empresa transnacional en el mercado global
}

\author{
Adalberto Cabello Chávez* \\ Rafael Reyes Avellaneda** \\ Pedro Solís Pérez***
}

\begin{abstract}
Resumen:
La aldea global es un mundo sin fronteras, sin límites, sin residencia, donde circulan libremente individuos, mercancías y capital. Las instituciones de la aldea global están conformadas por el estado regional, la empresa transnacional y el mercado global, de las cuales la que se acopla y domina a la aldea es la empresa transnacional, que utiliza diversas estrategias competitivas para controlar el mercado global a través de la organización multinacional con gestión centralizada y descentralizada y la organización global con gestión desconcentrada.
\end{abstract}

Palabras clave: aldea global, empresa transnacional y estrategia competitiva.

\section{Introducción}

E ste ensayo tiene como objetivo identificar y describir el funcionamiento de la aldea global; para lograrlo se hace una rigurosa revisión bibliográfica que permita identificar o encontrar las categorías de la aldea global. Por medio de este método se logro identificar y describir tres categorías: estado regional, empresa transnacional y mercado global.

\footnotetext{
* Profesor investigador titular, Departamento de Economía de la Universidad Autónoma Metropolitana, Unidad Iztapalapa. Correo electrónico: adalcabello@yahoo.com.mx

**Profesor investigador titular, Departamento de Economía de la Universidad Autónoma Metropolitana, Unidad Iztapalapa. Correo electrónico: rera462000@yahoo.com.mx

*** Profesor investigador titular, Departamento de Economía de la Universidad Autónoma Metropolitana,

Unidad Iztapalapa. Correo electrónico: pedrosolis53@prodigy.net.mx
} 
Adalberto Cabello Chávez

Rafael Reyes Avellaneda

Pedro Solís Pérez

De igual forma se busca describir y explicar el comportamiento de la empresa transnacional a través de un ejercicio lúdico donde se revisen tres conceptos: 1. estrategia (concepto de la empresa); 2. ser competitivo (posición ventajosa); y 3. estrategia competitiva (integración de los dos primeros conceptos). Estos tres conceptos se aplicaron a tres casos de estudio de empresas transnacionales mexicanas: Cemex, Coca-cola FEMSA; así como tres grandes en el sector automotriz en México: General Motors, Ford y Chrysler. Después de un análisis, se logró identificar y explicar las distintas formas de organización de las tres transnacionales. En la empresa Cemex se identificó una forma de organización multinacional con una gestión centralizada; mientras que en la empresa Coca-Cola FEMSA se encontró el modelo de organización multinacional y una gestión descentralizada; por su parte, en las tres grandes automotrices (General Motors, Ford y Chrysler) se percibió un modelo de organización global, con una gestión desconcentrada.

La hipótesis de trabajo que se maneja es la siguiente: identificar a la empresa transnacional como reguladora y ordenadora de la sociedad global; asimismo, a lo largo del ensayo se buscó probar esta afirmación, explicando las estrategias que emplea la empresa transnacional para regular o controlar el mercado global (sistema-mundo).

\section{La aldea global: una transformación del estado, el mercado y la empresa en el sistema-mundo, que orienta a la empresa a innovar su estrategia competitiva}

La aldea global es un mundo sin fronteras, sin residencia, sin límites, donde circulan libremente individuos, mercancías e inversión. La residencia de los participantes es donde se obtengan los máximos beneficios, esto es, su lugar de residencia es indefinido o indistinto. Si la inversión ${ }^{1}$ obtiene mayores frutos o ganancias, de un día para otro, en un lugar distinto, la inversión cambia de residencia; mientras que si los individuos obtienen mejores condiciones de trabajo, trasladan su residencia sin ningún titubeo. En este mundo sin fronteras, el mercado se ensancha, el mercado es global (sistema-mundo) y las mercancías se venden en los lugares más recónditos o subrepticios del mundo, al mejor postor, al que ofrece más de acuerdo con la ley de la oferta y la demanda.

${ }_{1}$ La inversión es propiedad privada, tiene un dueño, persona física o moral y tiene distintas opciones en el sistema-mundo (mercado global), para invertir tiene distintos portafolios o fondos financieros. Las transacciones financieras son electrónicas y cambian en cuestión de segundos de un lugar de residencia a otro en la aldea global, lo importante es obtener la máxima ganancia para el cliente, quien se trasladará al que ofrezca más y dé más sin ninguna restricción para mover el dinero. 
La estrategia competitiva que adopta la empresa

transnacional en el mercado global

La aldea global o sociedad global, una totalidad, es una aparente sociedad monolítica, sin diferencias, integrada a una sistema abierto ${ }^{2}$, a un sistema-mundo (mercado global). El sistema-mundo, entendido como un suprasistema, está formado por subsistemas y áreas regionales que se encuentran interrelacionadas, y a través de su integración se explica como un todo funcional. Las áreas regionales son zonas libres para hacer transacciones con inversión, mercancías y también con individuos ${ }^{3}$.

La aldea global —un mundo sin fronteras, una sociedad monolítica, regulada por el sistema-mundo (mercado global) - tiende a organizarse bajo esta filosofía de mercado, que trae implícito una cultura cosmopolita, universal, propia del sistema-mundo, interpretada como la integración de lo global y lo local (García Canclini, 1990). Las élites, constituidas por los individuos globales del sistema-mundo con su cultura global, aportan su estilo de vida.

\section{Mapa conceptual (1)} Aldea global: un mundo sin fronteras

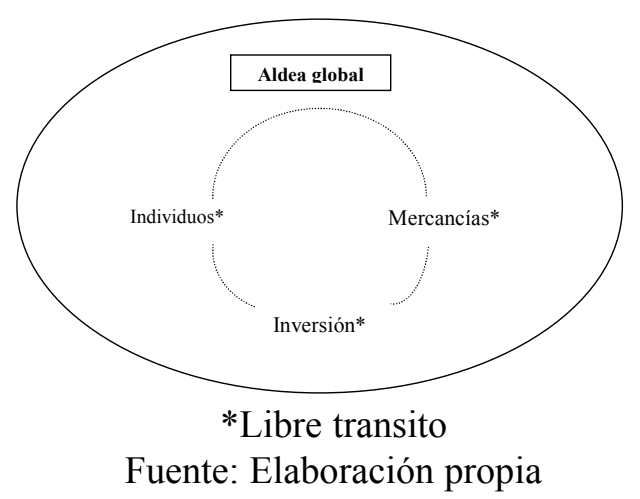

2 El sistema es entendido como un todo unitario-organizado, compuesto por dos o más partes, componentes o subsistemas interdependientes y delineados por los límites, identificables, con su ambiente o suprasistema (Kast y Rosenzweig, 1979). La relación entre los subsistemas se entiende a partir del funcionalismo, que es entendido como: "[...] los sistemas de interrelaciones y la integración de las partes o subsistemas en un todo funcional" (Kast y Rosenzweig, 1979: 110).

3 En las áreas regionales las transacciones son de todo tipo, no sólo de inversión o mercancías, se comercializa también con personas, pueden ser: niños y mujeres, los casos se conocen en la aldea global, las transacciones son ilegales, pero se realizan y se comercializan a las personas. A manera de ejemplo en mayo de 2005 en la Ciudad de México se descubrió a una banda de húngaros, que invitaban a sus compatriotas a ser modelos en México, y en realidad las ponían a trabajar como bailarinas en lugares de diversión (table dance), pero todo indica que muchas de ellas veían como mejor opción estar en México que en su propio país. 
Adalberto Cabello Chávez

Rafael Reyes Avellaneda

Pedro Solís Pérez

El individuo global de las élites tiende a ser cosmopolita y universal, prototipo de persona, en el cual todos los estratos deben reflejarse en él y ser como él. En México los $\mathrm{CIOs}^{4}$ (Chief Information Officer) son personas reconocidas por su éxito en los negocios, algunos calificados de individualistas y banales, como ejemplo tenemos a Jorge Vergara dueño en México de la marca Omnilife y del equipo de futbol soccer: Guadalajara; también es reconocido como comunicador y promotor de sus productos; sin embargo, para construir su complejo comercial y deportivo en Guadalajara solicita a los individuos que se reflejen en él, si quieren ser inmortalizados junto a su loseta con su nombre grabado; los individuos deben pagar \$2000.00 para que se grabe su nombre por siempre junto a él. Otro ejemplo muy reconocido es el CIO Carlos Slim, creador del grupo CARSO, el cuarto hombre más rico del mundo ${ }^{5}$, de comerciante al menudeo y mayoreo en el centro de la Ciudad de México llegó a consolidar su riqueza en el sector de las telecomunicaciones con sus empresas Telmex y AT\&T en América Latina. Él es un individuo que se dice preocupado por su entorno y por ello ha orientando sus empresas hacia la mercadotecnia social a través de la fundación Telmex y sus diferentes obras filantrópicas ${ }^{6}$.

La aldea global ha acortado las distancias y los tiempos, además ha acercado a los animadores (inversión, mercancías e individuos) a estar dentro de una localidad. La comunicación entre los individuos es virtual; se comunican en un instante, en espacios diferentes y en tiempos con horarios distintos. El avance tecnológico de las telecomunicaciones (fibra óptica) unido a la tecnología de la información (hardware y software) lo ha permitido, la realidad virtual es cotidiana y común en la aldea. La infraestructura de las metrópolis o mega ciudades se caracteriza por autopistas y puentes que comunican a las ciudades, puertos automatizados para descarga y carga, aeropuertos internacionales con servicios de cambio de divisas, salas de informática, y zonas de vuelos nacionales e internacionales, servicios de luz, agua, drenaje y telefonía. Esto hace a las mega ciudades o metrópolis compe-

4 Este individuo global de las élites en términos formales o de nomenclatura es reconocido como: CIO (Chief Information Officer). Según la página de la red de información: www.cio.com, la habilidad que se considera más importante para el éxito como CIO es la capacidad de comunicarse con eficacia. De 500 CIOs que participaron en una encuesta $70 \%$ escogieron la comunicación como una de sus tres habilidades más importantes, $58 \%$ eligieron entender el proceso y las operaciones del negocio y $46 \%$ pusieron el pensamiento estratégico.

5 Con el paso del tiempo todo indica que sólo estará a tras de Bill Gate y Microsoft.

6 Es reconocido el trabajo de la fundación Telmex en varios ámbitos: teletones, centros teatrales y organizaciones como origen, que ayuda a madres solteras, que son golpeadas físicamente y mentalmente, o becas para jóvenes que financian sus estudios. 
La estrategia competitiva que adopta la empresa

transnacional en el mercado global

titivas y atrae las inversiones directas a la producción. Los medios de comunicación: televisión, radio, periódicos, transmiten la información vía satélite o vía internet. La aldea global es entendida como una localidad o poblado con distancias muy cortas donde en cuestión de segundos o minutos entran en contacto los lugareños de una comunidad.

Dentro de esta aldea global tienden a desdibujarse o ser una desilusión instituciones ${ }^{7}$ como el Estado-nación, delimitadas a un territorio, a una población y a un gobierno común donde sus fronteras tienden a ser permeables y su tendencia es integrarse a la aldea global en el aspecto económico (mercado global ${ }^{8}$ ), político (estado regional ${ }^{9}$ ) y cultural (cultura global); es decir, integrarse a la sociedad global o sociedad mundo.

El Estado-nación es el fruto de la historia dentro de un territorio, en el caso de México de la fusión de dos culturas: prehispánica y española a partir de la cual se crea en el tiempo y obtiene una identidad nacional; en la actualidad se diluye esa identidad en la sociedad global y tiende a ser como parámetro, agente, realidad, pero también simplemente como una ilusión qué es o fue (Arellanes, 1997: p. 83). Las fronteras del Estado-nación son continua o periódicamente quebrantas, rehechas, rebasadas o disueltas.

De igual forma, ese Estado-nación es una ilusión dentro del mundo contemporáneo (siglo XXI); dentro de esta perspectiva nos dice Hernández (1997: p. 121), de acuerdo con Weber, que se define como aquella comunidad humana que, dentro de un determinado territorio, reclama (con éxito) para sí el monopolio de la violencia física legítima. Es así que para Weber el Estado-nación es una relación de control y monopolio del poder político, que lo ejerce a través de distintas instituciones: ejércitos tanto de carácter militar como administrativo, que legitiman el ejercicio del poder a través del derecho. En el caso de México el derecho es representado por la Ley Suprema, la Constitución de los Estados Unidos Mexicanos,

\footnotetext{
7 Se comprenderá por institución, la organización permanente o no perenne de orden público o privado, que regula según sea el caso la sociedad civil (gobierno federal y estatal), o en su caso el mercado (empresas transnacionales).

${ }^{8}$ El mercado global es el sistema-mundo o economía-mundo sin reglas para circular dentro de él, desregularizado, donde participan las empresas transnacionales (industrial, comercio y servicios).

${ }^{9}$ El estado regional, en este primer acercamiento, es entendido como: macroestado, al cual se integran los estados-nacionales, responsable de regular económica y políticamente a un área o bloque regional.
} 
Adalberto Cabello Chávez

Rafael Reyes Avellaneda

Pedro Solís Pérez

ocupando la cúspide, dentro de la jerarquía de las leyes. Esta perspectiva de Estado-nación, histórica y dominante durante gran parte del desarrollo capitalista (siglo XVI-siglo XX), que se colisiona y se diluye ante el embate de la sociedad global (última década del siglo XX hasta el momento actual 2005) que se fragmenta en distintas áreas regionales, ubicándonos dentro de una perspectiva sistémica, se opta por la sociedad mundo frente a las sociedades nacionales dentro del sistema político. Esto es, el Estado-nación no constituye en la actualidad la más alta autoridad dentro de un territorio, sino que es supeditado o dependiente a un Estado-regional, que es un aparato que se usa para ordenar o resolver política y económicamente problemas regionales para maximizar el consenso, minimizar la violencia y para manejar algunos problemas específicos. En la sociedad mundo, nos dice Luhmann según Hernández (1997), ya no tiene mucho sentido pensar en el Estado-nación como una categoría dominante, sino que el sistema político del mundo y los estados regionales de las áreas centrales delegan simplemente al Estado-nación el orden ${ }^{10}$ de sus territorios.

La aldea global o sociedad global regulada por el sistema-mundo (mercado global) esta formado por áreas o bloques regionales centrales: América del Norte, Unión Europea y el Bloque Asiático.

En el caso de América del Norte, el estado regional regula comercial y económicamente el área a través del Tratado de Libre Comercio de América del Norte (TLCAN) ${ }^{11}$, donde las reglas primordiales son: la libre circulación de mercancías e inversión, así como poseer un certificado de origen de los productos; es decir que los productos se fabriquen y el origen de sus insumos sea en un porcentaje

\footnotetext{
${ }^{10}$ Específicamente el orden social y la estabilidad macroeconómica, lo que atraerá la inversión extranjera directa y creará empleos con el consecuente crecimiento económico, o en su caso la inversión especulativa o sin residencia.

${ }^{11}$ En el caso específico de esta zona regional, y su institucionalización (Estado Regional de América del Norte), se tenía como objetivo obtener condiciones de equidad dentro de un mercado libre entre los tres países, ante el crecimiento desigual e inferior de México; es decir, mientras México sólo desgravó en 1994 el 43\% y 41\% respectivamente de las importaciones provenientes de Estados Unidos y Canadá, a México se desgravó inmediatamente el $84 \%$ y $79 \%$ de sus exportaciones mexicanas no petroleras respectivamente de Estados Unidos y Canadá, pero hay que aclarar que para el momento actual (2004) prácticamente el mercado es libre (en un 99\%) para los tres países (Reyes, octubre 1992). Pero sin lugar a dudas el TLCAN (la institución de regulación del Estado Regional) buscó y busca como fin estratégico y último beneficiar a los componentes del mercado regional: bancos transnacionales, empresas transnacionales y área regional. De esta manera les garantizará a éstos la certidumbre de un orden legal (respeto a la propiedad privada) y la estabilidad macroeconómica (precios, moneda), que proporciona en ambos casos el Estado-nación que garantice el capital invertido y su reproducción (capital + ganancia).
} 
La estrategia competitiva que adopta la empresa

transnacional en el mercado global

mayoritario perteneciente al área de América del Norte: Estados Unidos, Canadá y México. En el caso de controversias y disputas comerciales, éstas son resueltas por la comisión de arbitraje del TLCAN.

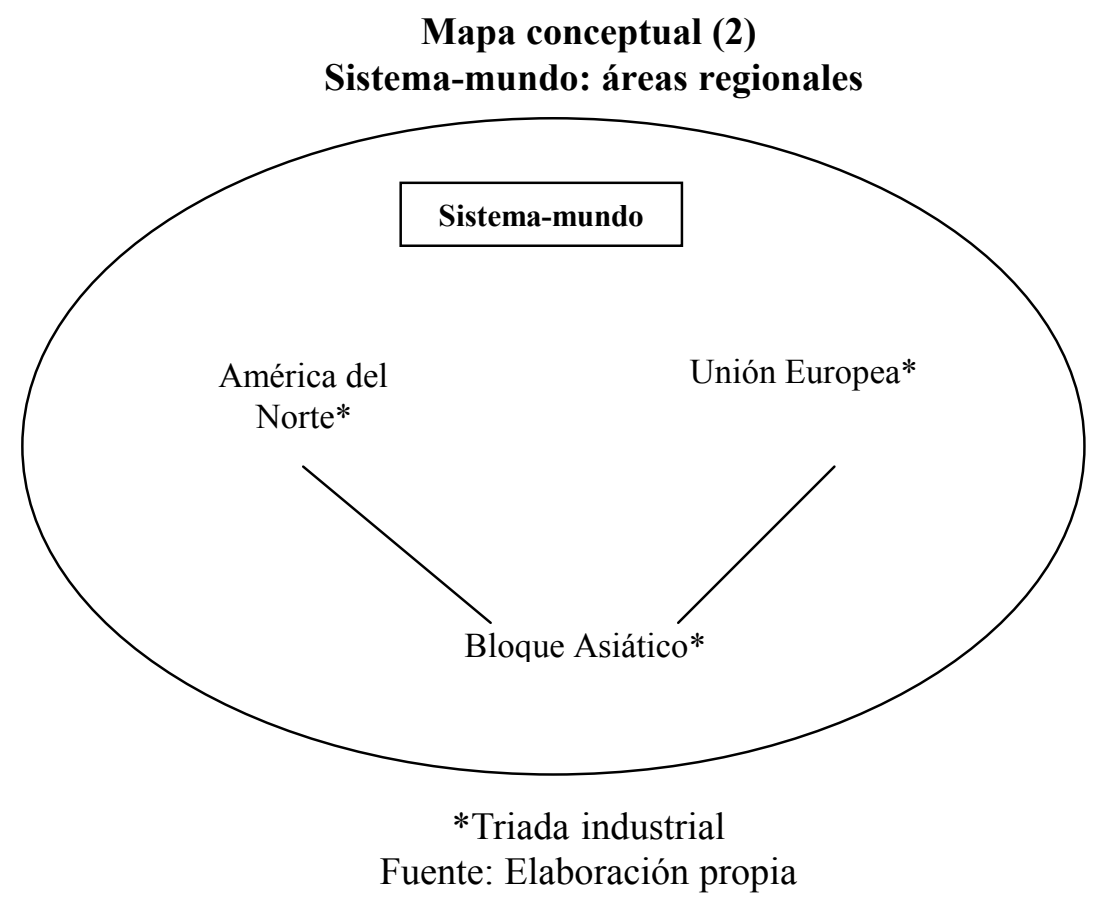

Con relación a la Unión Europea ${ }^{12}$, el estado regional más acabado, éste ha ido más allá de reglas de origen, comerciales y financieras que faciliten el libre transito, de insumos, mercancías e inversión. Asimismo, se ha dado un libre transito de individuos dentro del estado regional, además se tiene una moneda única (Euro) y un Banco Central y se ha aprobado por el comité ejecutivo de la Unión Europea un proyecto de constitución (2004) que está en proceso de consulta para todos los miembros que la forman ${ }^{13}$.

12 Actualmente en el 2005 la Unión Europea está formada por 25 países.

13 Hay que mencionar que el proyecto de la Unión Europea se basa en dos principios: orden macroeconómico y una misma filosofía política, lo que orientaría al estado regional a una formación perfecta, pero en la consulta o referéndum en dos estados nacionales importantes: Francia y Holanda; éstos (junio, 2005) han rechazado el proyecto de Constitución Suprema para la Unión Europea, aunque queda por esperar la decisión de los demás estados nacionales. 
En el caso del Bloque Asiático, que es reconocido en el sistema-mundo, existe la apertura del mercado regional que incluye a los llamados Tigres Asiáticos ${ }^{14}$, unidos a los líderes del área asiática: Japón, y China ${ }^{15}$. Este grupo de países con ventajas competitivas (infraestructura) ${ }^{16}$ y comparativas (tecnológicas) ofrece grandes atractivos para la inversión extranjera directa. En el caso de los Tigres Asiáticos, desde la apertura del mercado (1970-1994) orientado al sistema-mundo, han logrado triplicar su comercio: del 4.6\% al 12.5\% (PNUD, 1997).

Hay que aclarar también que la mayor parte de la Inversión Extranjera Directa (IED) está encaminada a la "triada" industrial de América del Norte, Europa, Japón y Beijing (China); esas economías recibieron (1994) más del 90\% de la IED mundial, mientras que el resto del mundo, con más del 70\% de la población, recibió menos del 10\% (PNUD, 1997).

Hay que mencionar que el papel de los estados-nacionales de las áreas periféricas, fuera de la triada industrial es no recibir inversión extranjera directa, no generar producción, no tener consumo y no generar riqueza.

Los animadores principales de este sistema-mundo (mercado global) son las empresas transnacionales y los bancos transnacionales, quienes se alían bajo la forma o método más avanzado para el capital que es el capital financiero:

La expansión de la industria capitalista desarrolla la concentración de la banca. El sistema bancario concentrado es también un motor importante para la consecución del grado superior de la concentración capitalista en los cartels y trusts. ¿Cómo repercuten éstos sobre el sistema bancario? El cartel o el trust es una empresa de gran potencia de capital. En las relaciones mutuas de dependencia de las empresas capitalistas es, sobre todo, la potencia de capital la que decide qué empresa cae bajo la dependencia de otra. Una cartelización muy avanzada motiva, desde un principio, que los bancos se asocien y aumenten para no caer

14 Se consideren dentro de los Tigres Asiáticos: Taiwán, Singapur, Malasia, Corea del Sur, Hong Kong.

15 China un caso muy raro, es un país gobernado por un partido comunista y el presidente del partido, además cuenta con un modelo ecléctico de mercado: regulado por el gobierno y de libre acceso.

16 Es importante destacar que la gran virtud de China es su ventaja competitiva en infraestructura y mano de obra barata, es un país en vías de desarrollo tecnológico. 
La estrategia competitiva que adopta la empresa

transnacional en el mercado global

bajo la dependencia del cartel o trust ${ }^{17}$. Así, pues, la misma cartelización fomenta la unión de los Bancos, como, por el contrario, la unión de los bancos promueve la cartelización. (Hilferding, 1971: p. 251)

Mapa conceptual (3)

Sistema-mundo: promotor del capital financiero

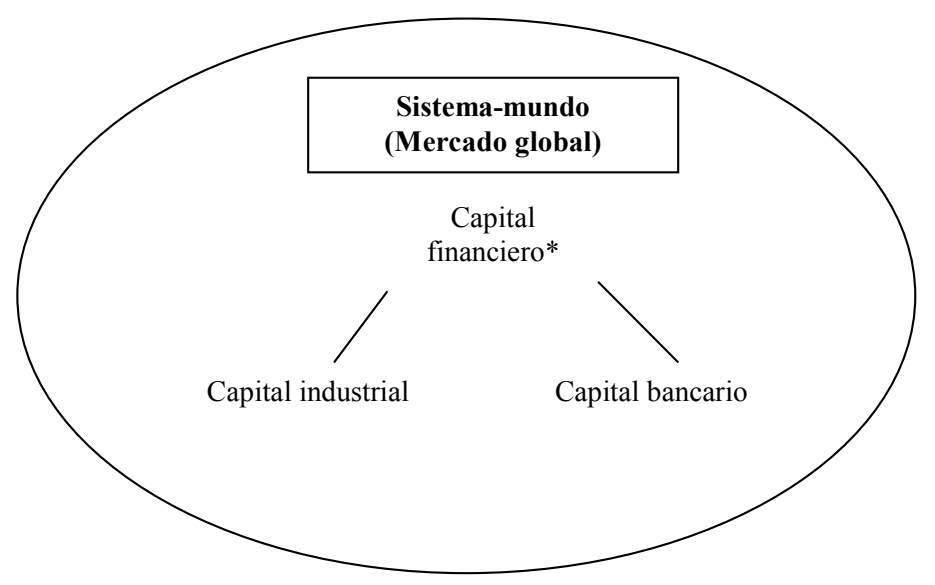

*Fusión: Método más desarrollado para el capital

Fuente: Elaboración propia

La cartelización significa también una mayor seguridad y regularidad del rendimiento de las empresas cartelizadas. Se han suprimido los riesgos de la competencia que, con frecuencia, eran antes muy peligrosos para la empresa individual. Pero de esta forma aumenta la cotización de las acciones de estas empresas, lo cual significa mayor ganancia de fundador en las nuevas emisiones. Además, es mucho mayor la seguridad para el capital invertido en estas empresas. Esto les permite a los bancos ampliar aún más su crédito industrial y, de este modo, participar en el beneficio industrial en mayores proporciones que hasta ahora. Así, mediante la cartelización, se estrechan aún más las relaciones entre los bancos y la industria, mientras que, al mismo tiempo, recae cada vez más sobre los bancos la disposición del capital invertido en la industria (Hilferding, 1971: p. 252-253).

17 En el caso de México, la expansión de la industria capitalista desarrolla la concentración de la banca, la cartelización de Bancomer (México) con el BBVA (España), fusionándose en México con el nombre: BBVABancomer, genera la fusión City Bank-Banamex, bajo el principio de que la potencia de capital es la que decide qué empresa cae bajo la dependencia de otra, lo que origina un efecto escalonado de que los demás bancos mexicanos se fusionen con bancos extranjeros. 
El mercado global como sistema-mundo, que se ubica en el enfoque sistémico, dice Arellanes (1997: p. 85), según Reynolds, es un "sistema económico internacional" donde sus componentes se mueven al interior de un sistema ordenado dentro de los mecanismos capitalistas. Los componentes de este sistema que son las empresas transnacionales y los bancos transnacionales se mueven a lo ancho del sistema-mundo e influyen en los aspectos sociales (económicos, culturales y políticos) de los estados-nacionales y en la conducta de los individuos e instituciones de la sociedad global; éstos reaccionan de acuerdo con el mecanismo conductista (estímulo-respuesta) de la institución económica dominante: la empresa transnacional; es decir, su dinámica es implementada y aceptada como propia y natural para los estados-nacionales y la sociedad global. Por su parte, Child (1972: p. 4), señala que no hay que dejar de lado la acción política de la organización; Galbraith afirma: "Donde las corporaciones transnacionales en la sociedad de la industria moderna, son capaces de manipular y crear su propia demanda, como centros de producción". Desde esta tesis, la corporación transnacional puede manipular su medio ambiente y darle su propio sello a la sociedad global a través de sus propios fetiches, de sus propios productos y servicios que se adoran por los individuos globales de la sociedad global.

\section{Mapa conceptual (4)}

\section{Empresa transnacional: manipuladora y creadora de demanda}

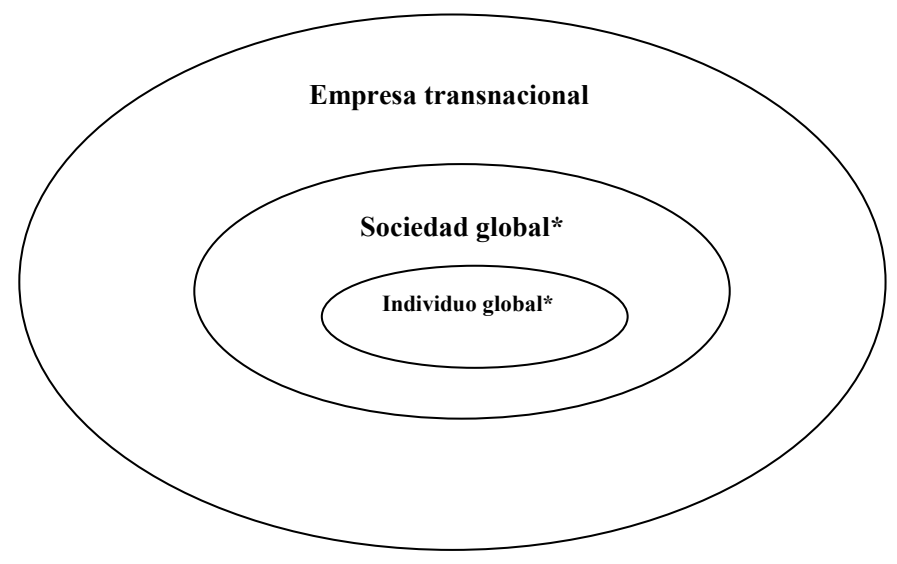

*Individuo global y sociedad global: subsistemas de la empresa transnacional. Fuente elaboración propia 
La estrategia competitiva que adopta la empresa

transnacional en el mercado global

Si nos ubicamos al interior de esta tesis o enfoque, las empresas transnacionales utilizan la estrategia del "desafío" (Mintzberg, et al., 1999) dentro de los procesos institucionales donde es clave la "indiferencia" de pasar por alto normas y valores explícitos de la sociedad en su conjunto; y donde también imponen el valor económico: concentración intensa de capital, así como los valores culturales: fetiches, a la aldea global.

Cabe aclarar que el concepto de empresa transnacional o corporación trasnacional es una categoría o concepto que se crea a partir de una estrategia o maniobra nueva de la gran empresa bajo las nuevas condiciones del medio ambiente; es decir, un mercado global o sistema mundo (1980-2005), lo que trae como consecuencia una forma de organización o estructura distinta, flexible, que le permita expandirse a lo largo y ancho del mercado global. El sueño de la empresa transnacional de un mercado sin fronteras se ha cumplido.

La categoría predominante de la gran empresa, anterior a esta época (1980 -2005), en el mundo y en México es distinta, pues era la empresa multinacional ${ }^{18}$ (19301970); la distinción no sólo es por el nombre, sino por el contexto y sesgos de este tipo particular de empresa.

En cuanto al caso particular de México, dice Cabello y Reyes (Julio, 2003: 70), de acuerdo con Tello, se distingue el modelo de organización económica por un mercado protegido, bajo un política del Estado-nación de sustitución de importaciones, una política que prevalece después de la Segunda Guerra Mundial hasta los años setenta que limita el mercado local a un espacio territorial o nacional, que impone barreras arancelarias y no arancelarias ${ }^{19}$ a la inversión extranjera directa. Se garantiza entonces un mercado local de tipo cautivo oligopólico, que beneficie

\footnotetext{
18 La empresa multinacional es un tipo de forma o estructura organizacional particular, que responde bajo una estrategia o astucia o arte a un medio ambiente distinto que es un mercado local (1930-1970), que se consolida en el mundo en los años 1960 y 1970, donde bajo este principio económico y la concesión política de los estados-nacionales se permite trasladar la empresa multinacional a otros países. La empresa multinacional se rige bajo dos principios distintivos: multinacional, que consiste en multiplicar la organización en estadosnacionales. Por su parte, la forma de organización o estructura es a través de filiales o subsidiarias (organización multinacional) utilizadas en cualquiera de los sectores económicos: industrial, comercial y de servicios.

19 Por barreras arancelarias se entenderá como barreras basadas en altos impuestos, cuotas restrictivas de productos de importación hasta en un $100 \%$; mientras que por barreras no arancelarias se comprenderá como la negación de permisos de bienes de importación por el interés nacional.
} 
Adalberto Cabello Chávez

Rafael Reyes Avellaneda Pedro Solís Pérez

territorialmente a la inversión interna y que sólo en ciertos sectores económicos permitiera el acceso al capital extranjero, garantizando primordialmente el desarrollo de un mercado interno y de los productores o capital nacional.

El dominio de los mercados nacionales era de tal forma, que sólo a través de acuerdos entre estados-nacionales se podía permitir la expansión de las empresas multinacionales. El cuidado del buen comportamiento de este tipo de empresas tenía tal seguimiento que la misma Organización de las Naciones Unidas (ONU) hizo una comisión de las empresas multinacionales y un código de conducta a solicitud de los estados subdesarrollados (Arellanes, 1997: 143). Durante las décadas de los sesenta y setenta, aun cuando los estados nacionales de América Latina no simpatizaban abiertamente sus intereses nacionales con los intereses de la empresa multinacional, ésta utilizaba la estrategia de acceder a estos mercados nacionales por la vía de la negociación política con los gobiernos.

La estrategia o maniobra de penetrar en los mercados locales que pone en práctica la empresa multinacional, en el sector manufacturero, es la de trasladar la empresa matriz (país de origen) como empresa filial o subsidiaria (país destino), lo que origina una presencia por lo menos en dos países. En este caso, el arte es trasladar el proceso productivo a escala de un país a otro con toda la infraestructura (bienes de capital) y saber hacer operativo (know how) sólo utilizando la mano de obra local.

Específicamente, la estrategia de penetración en México de la empresa multinacional la explica Ramírez (Enero, 1997: 29) a través del modelo Shelter, que es fundamentalmente un régimen legal de exportación instrumentado en 1965 por el gobierno de México para atraer empresas interesadas en subcontratar servicios de transformación. Este modelo Shelter básicamente se inicia con el envío de partes importadas (insumos y maquinaria), libres de impuestos, de las plantas gemelas ubicadas en Estados Unidos a las maquiladoras en México. Estas ensamblan las partes y las retornan a la planta gemela, quien hace llegar los productos a la empresa matriz directamente o a través de un intermediario; éste es el más puro comercio intraempresa.

Con respecto a la empresa transnacional en el sector manufacturero (sector automovilístico) y su estrategia de operar en el mercado global y en el sistema-mundo, nos dice Ramírez (Enero, 1997: 31), es el complejo flexible (organización global) o complejo justo a tiempo (JAT) donde la empresa desintegra el proceso produc- 
La estrategia competitiva que adopta la empresa

transnacional en el mercado global

tivo a través de empresas matrices, empresas filiales o subsidiarias, empresas independientes, al más complejo comercio, intraempresa e interempresa. Posteriormente, el proceso se reintegra a través de centros de consolidación y empresas ensambladoras. En el caso de México y el sector automotriz, simplificando en un primer acercamiento ${ }^{20}$, hay empresas maquiladoras pertenecientes a las empresas gemelas en EU, ubicadas en México (comercio intraempresa). Asimismo, se presentan empresas independientes de propiedad estadounidense, japonesa y alguna mexicana (comercio interempresa). Estas empresas pueden contar con empresas subsidiarias o filiales (comercio intraempresa). La cadena se extiende a una infinidad de proveedores de primer, segundo, tercer, etc., niveles.

La aldea global —un mundo sin fronteras, sin límites en la organización económica del mercado que adopta, que es el sistema-mundo o mercado global - ha cumplido con el sueño de la empresa transnacional: acceder al mercado total manipulándolo y dominándolo. La repercusión más significativa es la adaptación de la sociedad a la empresa transnacional, lo cual se muestra claramente en los siguientes datos: de las 100 economías más grandes del mundo cincuenta son mega empresas. Corresponde actualmente a las 350 mayores empresas el 40\% del comercio mundial, además su volumen de negocios (ventas) es mayor que el PIB de muchos países (PNUD, 1997).

Más específicamente Chudnovsky y López (1999: p.13), conforme a la United Nations Conference on Trade and Development (UNCTAD, 1998), destacan que en 1997 se estimaba "que 450,000 filiales en el extranjero - correspondientes a 53,000 empresas transnacionales- generaban un producto bruto (PB) equivalente al $7 \%$ del PB mundial. Asimismo, sus ventas eran casi el $50 \%$ superiores a las exportaciones mundiales de bienes y servicios". Por tanto, las ventas de las empresas transnacionales equivalen a 1.5 veces de las exportaciones mundiales. Adicionalmente, los mismos autores señalan, de acuerdo con la Organización Mundial de Comercio (OMC, 1996), que "el comercio intrafirma de las empresas transnacionales representa cerca de la tercera parte del comercio mundial y las exportaciones de las empresas transnacionales a firmas que no son filiales suyas representan otra tercera parte de dicho comercio".

\footnotetext{
20 Más adelante se explicará de una manera más especifica el funcionamiento de la empresa transnacional por medio de este modelo de organización global.
} 
Adalberto Cabello Chávez

Rafael Reyes Avellaneda

Pedro Solís Pérez

\section{Estrategias competitivas de la empresa transnacional, su diversidad en el mercado global}

Describir y analizar la categoría de aldea global como la integración de comunidades nacionales en una comunidad global es un apartado fundamental para comprender el funcionamiento del sistema-mundo (mercado global). Las categorías utilizadas (Estado, mercado y empresa) son claves para explicar este complejo y complicado sistema global. Este análisis ha sido fundamentalmente socioeconómico y dentro de este contexto (suprasistema) hay que comprender la estrategia competitiva de la empresa.

El concepto integral de estrategia competitiva hay que concebirlo, en un primer lugar, separando los conceptos de estrategia y ser competitivo (competitividad); en segundo lugar, uniéndolos como un todo, en un significado indisoluble ${ }^{21}$.

La estrategia es un concepto tan viejo y antiguo como la guerra; entenderlo significa saber ubicar al ejército en el campo de batalla. La estrategia se reconoce entonces, como "la habilidad, la pericia, para ubicar y mover al ejército en el campo de batalla con el fin no sólo de competir sino de ganar", es decir, no tendría ningún sentido la estrategia, sino se obtiene ganar. En todas las actividades de la aldea global, en la actividad social, ya sea la economía, política y cultura no tendría sentido participar, sino se gana. No sólo es una cuestión ideológica de la sociedad global, es la única máxima o ley que existe: "ganar, ganar y ganar", sino eres separado, desagregado de la sociedad, es decir segregado. Con respecto a la destreza para posicionar al ejército en el campo de batalla Tzu, $\operatorname{Sun}^{22}$ (2003: 9) afirma:

[...] si el jefe está dotado de sabiduría, será capaz de reconocer los cambios de las circunstancias, actuar con presteza. Si es equitativo, sus hombres estarán seguros de la recompensa y del castigo. Si es humano, amará al prójimo, compartirá sus sentimientos y apreciará su trabajo y sus dificultades. Si es valiente, alcanzará la victoria captando, sin dudarlo, el momento oportuno. Si es severo, sus tropas serán disciplinadas, porque temerán y recelarán el castigo.

21 Es indudable que el juego de palabras, interpretando el significado de ellas, deduce a comprender o entender el concepto.

22 Sun Tzu, escribió el Arte de la guerra 500 años antes de Cristo. 
La estrategia competitiva que adopta la empresa

transnacional en el mercado global

Para gobernar y dirigir a un ejército hay que ser flexible y vertiginoso para adaptarse a las circunstancias, nos dice Sun Tzu, (2003, p.31); según Chang Yu: "La bondad y la justicia pueden servir para gobernar un Estado, pero no para la administración de un ejercito. La presteza y la flexibilidad pueden servir para administrar un ejercito, pero no para gobernar un Estado". El fin, sin lugar a dudas, de la estrategia es la victoria, al respecto menciona Sun Tzu, (2003, 18-19):

La victoria es el principal objetivo de la guerra. Si tarda demasiado en llegar, las armas se embotan y la moral decae. Cuando las tropas ataquen a las ciudades estarán en el límite de sus fuerzas [...] Si tus armas han perdido el filo, si tu ardor se extingue, si tus fuerzas se agotan y si tu tesorería ha quedado reducida a nada, los soberanos vecinos se aprovecharán de tu apuro para actuar. Y aunque tengas consejeros sagaces, ninguno de ellos será capaz de trazar planes adecuados para el futuro.

En el campo de batalla se da la competencia: "la participación de jugadores o enemigos que rivalizan y luchan por ganar el territorio o la tierra", lo más preciado para el hombre. El fin de la competencia (estrategia) es ganar. ¿Cómo ganar a los participantes siendo competitivo?; ser competitivo (competitividad) significa: "el arte o maestría de participar en la guerra, buscando una posición ventajosa sobre los otros participantes".

Lo primero es conocer las fortalezas y debilidades como participante; si no se conoce uno a sí mismo, es decir, si no hay un general que sepa dirigir a su ejército, uno se inmovilizará y no tendrá posición ventajosa. En relación con esto nos dice Sun Tzu, (2003, 31), según Wang Shi:

[...]Si una persona que ignora las cuestiones militares es enviada para intervenir en la dirección del ejercito, cada movimiento despertará el desacuerdo y la frustración recíprocos, y todo el ejercito se paralizará. Por esto, Pei Tu presentó una queja al trono para que fuese destituido el supervisor del ejercito; solamente después de esto estuvo en condiciones de pacificar Ts'ao Chou.

Lo segundo es el arte de buscar una posición ventajosa, lo cual se obtiene, nos dice Sun Tzu, (2003:11-12):

[...] por situaciones entiendo que debe actuar con presteza de acuerdo con lo que sea ventajoso convirtiéndose así en el dueño del equilibrio [...] todo el arte de la 
Adalberto Cabello Chávez

Rafael Reyes Avellaneda

Pedro Solís Pérez

guerra está basado en el engaño. Por esto cuando seas capaz, finge la incapacidad; activo, la pasividad. Próximo, haz creer que estás lejos; alejado que estás cerca. Ofrece un señuelo a tu enemigo para hacerle caer en una trampa; simula el desorden y sorpréndelo...si el general del ejercito enemigo es obstinado y propenso a la cólera, insúltale y haz que se enfurezca, de manera que este irritado, que ya no vea claro y que se lance atolondradamente sobre ti, sin plan. Finge estar en inferioridad de condiciones, estimula su arrogancia.

Lo tercero es ser competitivo a través de las alianzas; une fuerzas y vencerás, menciona Sun Tzu (2003: 26), según Wang Hsi:

[...] Examina la cuestión de sus alianzas y provoca su ruptura y dislocación. Si un enemigo tiene aliados, el problema es grave y la posición del enemigo, fuerte; si no los tiene, el problema es menor y su posición, débil.

La estrategia competitiva "es la habilidad o destreza para ubicar y mover al ejercito en el campo de batalla, buscando obtener una posición ventajosa, conociéndose primero así mismo, engañando al enemigo y destruyendo sus alianzas." Si integremos el concepto tenemos que este primer acercamiento nos permite comprender la estrategia competitiva en su medio ambiente natural: la guerra. Ahora traslademos el concepto a la empresa; para Ansoff (1976: p.135-136) el concepto de estrategia es nuevo relativamente en los escritos sobre la dirección de empresas. Confirma que históricamente comenzó en el arte militar donde es un grand $^{23}$ concepto amplio y vagamente definido de una campaña militar para la aplicación de fuerzas en gran escala contra el enemigo ${ }^{24}$.

En 1948 Von Neumann y Morgenstern, con su ahora famosa teoría de juegos, iniciaron el uso de la estrategia en el mundo de los negocios; esta teoría proporciona una visión unificada para todas las clases de situaciones conflictivas sin tener en cuenta si su origen es la guerra, la política o el negocio. Se dan dos significados al concepto de estrategia. En primer lugar, la estrategia pura es un movimiento o una serie específica de movimientos de una empresa, tal como el programa de desarrollo de un producto, en el que se describe claramente hacia dónde se va a dirigir el producto, es decir, hacia qué mercados sucesivos.

23 Una grand estrategia o estrategia mixta es una regla estadística de decisiones para decidir qué estrategia pura particular debería escoger la milicia en una situación particular.

24 La táctica se contrapone, es más bien específica y se refiere al empleo (operación) de los recursos asignados. 
La estrategia competitiva que adopta la empresa

transnacional en el mercado global

\section{Mapa conceptual (5) Estrategia competitiva: arte de la guerra}

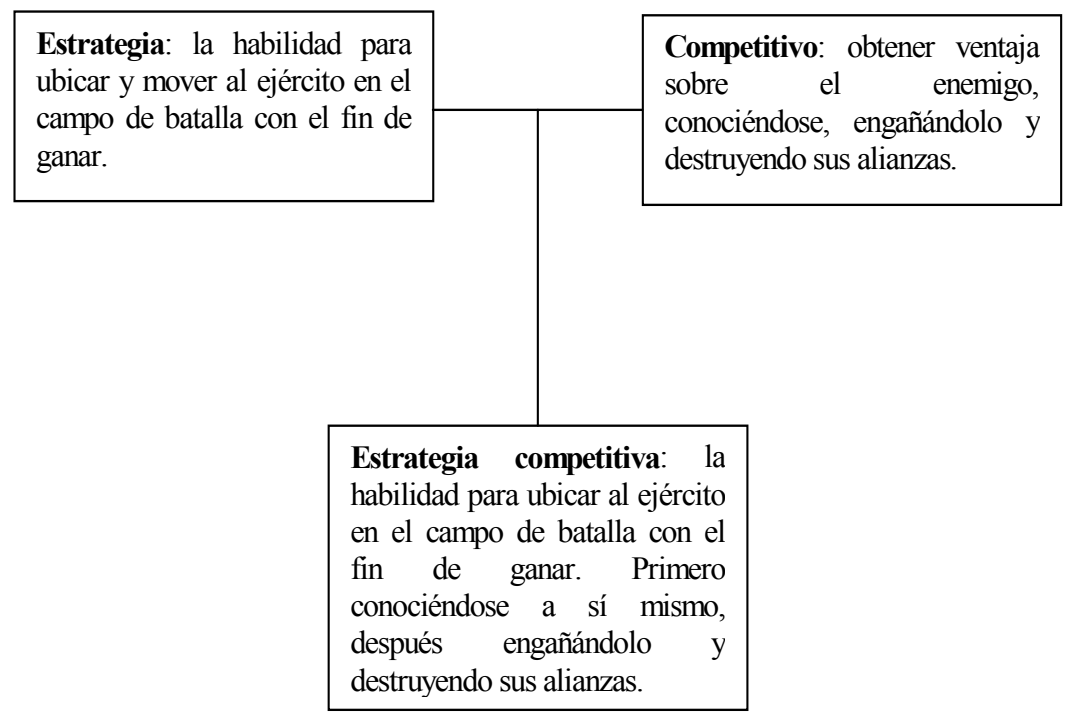

Fuente: Elaboración a partir de Sun Tzu (2003)

La estrategia es interpretada como: "la dirección de la empresa para dirigir sus productos hacia qué posiciones del mercado, con el fin de ganar el mercado"; dirigir los productos hacia el mercado implica riesgo e incertidumbre, pero hay que responder con reglas estadísticas de decisiones. Se identifica así el segundo significado de la estrategia, una grand estrategia o estrategia mixta es una regla estadística de decisiones para decidir qué estrategia pura particular debería escoger la empresa en una situación particular. Esta estrategia, en el contexto de este ensayo, es encontrar la posición ventajosa (ventaja competitiva) para vencer al enemigo; es decir, ser competitivo (competitividad) se entiende como: "buscar una ventaja competitiva para vencer al adversario en el mercado".

Por otra parte, la estrategia la define Ansoff (1976: 137-138) como: "[...] una regla para la toma de decisiones [...] que requiere un criterio final ejecutivo, es anticipar el suceso, con la probabilidad de un posible resultado", más adelante nos dice: "nosotros hablamos de decisiones estratégicas cuando estratégicas quiere 
Adalberto Cabello Chávez

Rafael Reyes Avellaneda Pedro Solís Pérez

decir relaciones con el acoplamiento de la empresa a su entorno, y de estrategia cuando la palabra significa reglas para decisiones en ignorancia parcial. Desde estos dos conceptos, es indudable que, desde el esquema utilizado en el ensayo, es oportuno definir el término competencia como concepto intermedio, el cual podemos decir que es: "el lugar (mercado) donde participan los jugadores o empresas con el objetivo de ganar el mercado". Podemos concluir (Ansoff, 1976: 123-124) que: "[...] una empresa necesita una dirección de expansión y ámbito bien definidos, que los objetivos solos no satisfacen esta necesidad y que se requieren reglas de decisión adicionales si la empresa quiere tener un crecimiento ordenado y rentable". La dirección tiene y debe buscar como tarea principal nuevas oportunidades en el mercado.

Para ser competitivo (competitividad) y encontrar una posición ventajosa ante el adversario, primero la empresa se debe conocer a sí misma; esto es, debe tener claro a qué se dedica y cómo se vincula con el mercado, es decir, su misión. Nos dice Ansoff (1976:124-125) que Levitt ${ }^{25}$ sugiere que se necesita una descripción más definitiva del papel de la empresa en su entorno para su expansión y éxito. Tal descripción tiene que abarcar una amplia perspectiva de las extensiones naturales de la posición producto-mercado de la empresa derivadas de algunas características clave del negocio actual. Así, por ejemplo, los ferrocarriles se definirían como negocio de transporte; sin embargo, Ansoff (1976) va más allá, pues nos dice que es un concepto muy amplio y no proporciona lo que la comunidad de inversiones llama vínculo común, "una relación entre el producto-mercado actual y el futuro" que capacitaría a los extraños para percibir hacia donde se dirige la empresa y a la dirección interior para guiarla. También este mismo autor afirma (1976:125-126) que hay que hacer una distinción entre clientes y misiones (mercados). Una misión (mercados) es una necesidad de un producto existente, mientras un cliente: "es el comprador actual del producto, la unidad económica (individual, familiar, empresarial) que tiene la necesidad y el dinero requeridos para satisfacerla"; es decir, no hay que confundir al cliente como vínculo común del negocio de la empresa, sino que hay que identificar perfectamente la ubicación del mercado actual y futuro. De esta manera vinculamos al ferrocarril (negocio de transporte) a la necesidad que existe de este medio.

25 Ansoff hace referencia al afamado artículo de Levitt (julio-agosto, 1960), "Marketing miopía", Harvard Business Review, vol. 38, no.4, pp. 45-46. 
La estrategia competitiva que adopta la empresa

transnacional en el mercado global

Si consideramos lo anterior, entonces diríamos que el ferrocarril como negocio de transporte se liga a la misión (mercado posible): transporte interurbano por tierra, para transporte de carga; en este momento se debe vincularlo al cliente empresarial o gubernamental. Así, el producto es el ferrocarril como transporte; el mercado es transporte interurbano de carga; y el cliente es empresarial o gubernamental ${ }^{26}$. Asimismo, es el momento de decidir hacia dónde se dirige el producto-mercado actual, "el ferrocarril interurbano de carga", al producto-mercado futuro; podemos decir - reconociendo que es vago en este momento del ensayo, o débil pero válido para construir el seguimiento- que el ferrocarril interurbano de carga se dirige a un elevado ritmo de crecimiento, lo que lo hace una empresa en expansión, es decir, busca desarrollar el mercado ${ }^{27}$. Después de ubicar al negocio de ferrocarril en una posición en el mercado y hacia donde se dirige ahora corresponde contestar ¿cómo obtener esa ventaja competitiva o posición ventajosa en el mercado, es decir: ¿cómo ser competitivo (competitividad)? Siguiendo con el ejemplo anterior, lo podemos lograr a través de la economía de escala ${ }^{28}$, aumentando la infraestructura de ferrocarriles y la dimensión adecuada de los vagones para transportar grandes lotes de carga, desde acero u otro mineral (cobre, plata) hasta granos (trigo, maíz y fríjol) para bajar los precios del transporte por volumen y obtener una posición ventajosa en el mercado. Se estima que los costos de transporte por ferrocarril son 200 veces menores en comparación con transportes de carga terrestres como traileres o transportes de redilas; posteriormente, se debe buscar una estrategia particular complementaria para mejorar la economía de escala para el negocio de ferrocarril mediante alianzas con otros negocios del ramo, esto para incrementar el volumen de transacciones o la cantidad de transacciones y fusionar con otras empresas los recursos de capital (maquinaria y equipo) de trabajo (capacidad física y mental) y de conocimiento del negocio (organización y dirección). A través de este ejemplo podemos ubicarnos en las distintas estrategias competitivas que siguen las empresas transnacionales en el mercado global, utilizando como ejemplo las empresas localizadas en México que se extienden en todo el mercado global.

26 Definimos el producto-mercado actual con base en un ejemplo que puede seguir otra ruta: ferrocarril como transporte, mercado: transporte interurbano de pasajeros y el cliente: individual o familiar.

27 Más adelante, en el momento oportuno, aclararemos esta debilidad del ejemplo.

28 La estrategia de economía de escala se observa como una estrategia económica y se entiende como "aumento del tamaño de la planta, de la empresa o del sector, que presupone un avance tecnológico que permite aumentar la producción y la productividad". Las consecuencias o ventajas competitivas son ahorro de los factores productivos debido al tamaño de la planta o disminución del número de empresas en el mercado (alianza). 
Iniciemos por la empresa Cemex (Cementos Mexicanos), fundada en 1931 gracias a la fusión entre Cementos Hidalgo S.A. y Cementos Pórtland Monterrey (Serrano, mayo 2005: 42). Durante los años setenta, Cemex concentró su crecimiento en el interior del país (mercado local), propio del modelo económico de esa época de sustitución de importaciones a través de la expansión de su capacidad productiva (economías de escala), así como de una estrategia de compras y fusiones (alianzas), lo cual le permitió consolidarse como una de las principales cementeras mexicanas ${ }^{29}$.

\section{Mapa conceptual (6)}

\section{Estrategia competitiva: arte de la empresa}

\begin{tabular}{|l|l|l|}
\hline $\begin{array}{l}\text { Estrategia: es definir el } \\
\text { concepto de la empresa } \\
\text { (producto-mercado actual) y } \\
\text { hacia donde se dirige } \\
\text { (producto-mercado futuro). }\end{array}$ & $\begin{array}{l}\text { Competitivo } \\
\text { posición ven } \\
\text { una estrat } \\
\text { (economía } \\
\text { situación pa } \\
\text { del mercado) }\end{array}$ \\
$\qquad \begin{array}{l}\text { Estrategia competitiva: es el } \\
\text { concepto de la empresa: producto } \\
\text { (ferrocarril, interurbano, de carga), } \\
\text { mercado (empresas yobierno); se } \\
\text { dirige al mercado futuro (desarrollo } \\
\text { del mercado), obteniendo una } \\
\text { posición ventajosa a través de la } \\
\text { estrategia (economías de escala y } \\
\text { alianzas). }\end{array}$ \\
\hline
\end{tabular}

Fuente: Elaboración a partir de Ansoff, H. Igor (1976)

29 Esta estrategia de economías de escala y alianzas en el mercado local (República Mexicana) es propia de los años setenta donde Cemex, incorpora a las cementeras nacionales: Cementos Guadalajara, Cementos Anáhuac y Cementos Tolteca, su principal competidor. 
La estrategia competitiva que adopta la empresa

transnacional en el mercado global

Actualmente, Cemex (2005) en el mercado global tiene participación en cincuenta países en el mundo con cuatro divisiones regionales (unidades estratégicas de negocios): región norteamericana y trading (operaciones en México y Estados Unidos), región Europa (operaciones en Reino Unido, Francia, Alemania, el resto de Europa —excepto España, Portugal e Italia — e Israel), región iberia, Medio Oriente, África y Asia (operaciones Península Ibérica, Italia, África y Asia, incluyendo los Emiratos Árabes Unidos y Malasia) y región Sudamérica y el Caribe (operaciones en Sudamérica y el Caribe) (Serrano, mayo 2005: p. 44).

Cabe señalar que el consejo de administración de Cemex tiene muy claro el concepto de empresa en el que se ubican: "[...] saben que lo esencial es la producción del cemento. Y que el resto del despliegue de su impresionante compañía tiene su base sólida, consistente en esta actividad" (Serrano, mayo 2005: 43). "Desde la simple combinatoria de arcilla y piedra (los principales componentes del cemento) se consiguió erigir una compañía comercial que ahora encabeza a las transnacionales nacionales" (Serrano, mayo 2005: 42). Esto significa que su producto actual es: "[...] la producción y comercialización de cemento y concreto premezclado"30; en tanto su mercado actual es global con posiciones en América, Europa, Asia, África y Medio Oriente; además, su forma de comercializar el cemento y concreto premezclado en México es a través de la entrega de cemento las 24 horas del día por medio de mayoristas y detallistas y de distribuidores certificados: Construrama, con 2,100 puntos de venta en todo México.

Es importante hacernos algunos cuestionamientos: ¿Hacia dónde se dirige el producto-mercado futuro?, hacia el uso de materias primas alternas en el proceso de producción de cemento y ha promover nuevos usos del cemento en sustitución de otros materiales de construcción. En mercados como el de México, Estados Unidos y España se están pavimentando carreteras con concreto, lo cual brinda mayor durabilidad y requiere de menos mantenimiento que el asfalto, además hay un costo integral más bajo. Por lo tanto, el mercado futuro es penetrar más en los mercados locales actuales y desarrollar nuevos mercados ${ }^{31}$.

30 La fuente de esta información es la página de internet de Cemex: www.cemexmexico.com.

31 Es el momento de decir que Ansoff (1976: 128) define 4 estrategias para expandirse en el mercado: 1. Penetración en el mercado (producto actual - misión o mercado actual); 2. Desarrollo del mercado (producto actual - misión o mercado nuevo); 3. Desarrollo del Producto (producto nuevo - misión o mercado actual); 4. Diversificación (producto nuevo - misión o mercado nuevo). En el caso del ejemplo del negocio de ferrocarriles se eligió de manera aleatoria para expandirse en el mercado la estrategia de "Desarrollo del mercado". 
Adalberto Cabello Chávez

Rafael Reyes Avellaneda

Pedro Solís Pérez

¿Por qué es competitivo Cemex? Su posición ventajosa o ventaja competitiva es de comprar o fusionar otras empresas de cemento, lo que incrementa el tamaño de la empresa - o de las unidades estratégicas de negocios - , lo que le otorga la ventaja de "economías de escala"; sin embargo, esta transnacional mexicana utiliza estrategias puras y particulares - de acuerdo con Ansoff (1976:136) - que van más allá del tamaño de empresa; también utiliza la estrategia administrativa ${ }^{32}$ : "liderazgo de costos" que normalmente implica sistemas de control muy estrechos, minimización de gastos generales, seguimiento de economías de escala y dedicación a la curva de aprendizaje (Porter 1997: 41). Esta curva es interpretada por Porter (1999: 30) de la siguiente manera: "[...] se refiere a la eficiencia conseguida a través del tiempo por los trabajadores, después de muchas repeticiones". Así, Cemex ya se caracterizaba: "desde los años 1970s [...] por la implementación de elementos tecnológicos que permitían controlar las operaciones de la compañía y mejorar los tiempos de rotación del dinero. Quizás, uno de los mayores atractivos empresariales de Monterrey era la oficina de Lorenzo Zambrano, quien desde su escritorio podía supervisar las operaciones de todas las plantas" (Serrano, mayo 2005: 43) $)^{33}$.

Es pertinente aclarar que la empresa transnacional Cemex se desarrolló dentro de los mercados locales en el nivel mundial a través de la estrategia económica conocida como economías de escala y alianzas. Su experiencia y desarrollo en el mercado local mexicano le permite desarrollar en los distintos países, en un segundo tiempo, una estrategia administrativa de liderazgo de costos: minimización de gastos generales, control estrecho y curva de aprendizaje. En 2005, ante su consolidación como empresa transnacional, en un tercer tiempo, es más propio definir la estrategia como una estrategia de sistemas ${ }^{34}$ : de sinergia, entendida como "[... a este efecto que produce un resultado combinado de los recursos de la empresa,

32 Esta estrategia va más allá de la estrategia económica del tamaño de planta y se diferencia por ser una estrategia administrativa.

33 Esta empresa transnacional, con un modelo de organización multinacional (Matriz - Filiales o Unidades Estratégicas de Negocios [UET]), tiene una gestión centralizada: 1. Mentalidad internacional: operaciones internacionales tratadas como apéndices de la corporación central; 2. Federaciones coordinadas: muchos activos, recursos responsabilidades y decisiones descentralizadas, pero controladas desde la central; 3 . Control administrativo: la planificación de la gestión y los sistemas formales de control permiten un vínculo más estrecho central-filial (Bartlett y Ghoshal, 1991: p.58).

34 La teoría general de sistemas y sus conceptos básicos fueron establecidos por el biólogo Ludwing von Bertalanffy en el estudio general:"The Theory of Opens Sistems in Physics and Biology", en Science, 13 de enero de 1950, pp. 23-29. Esta teoría se utiliza como un método para entender o comprender cualquier área del conocimiento científico. 
La estrategia competitiva que adopta la empresa

transnacional en el mercado global

mayor que la suma de sus partes...<2+2=5>" (Ansoff, 1976: 100-102). Específicamente la estrategia pura particular o ventaja competitiva es sinergia de dirección, cuyo significado es: "[...] la dirección se encuentra al crecer hacia otras áreas geográficas, y al identificarse con productos similares, con problemas estratégicos y operativos similares. Estando en posición ventajosa, la dirección, para guiar de manera enérgica y efectiva a la empresa recientemente adquirida. Ya que una alta dirección competente, es un bien escaso".

Mapa conceptual (7)

Estrategia competitiva: arte de la empresa transnacional Cemex

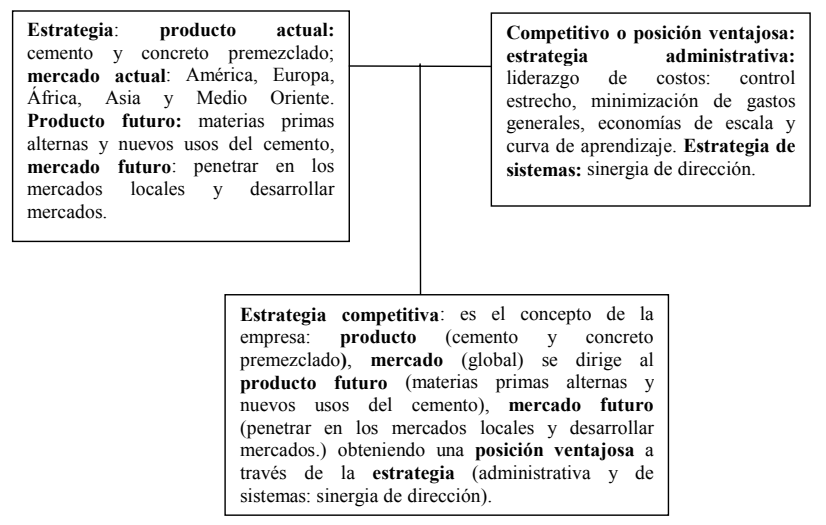

Fuente: Elaboración propia

Por lo que respecta al análisis de FEMSA (Fomento Económico Mexicano, SA de CV), su director general actual es José Antonio Fernández Carbajal (Juárez, mayo 2005: 36), tiene una estructura divisional (Unidades Estratégicas de Negocios), que en su primer nivel cuenta con las siguientes divisiones: Dirección General Operativa (FEMSA Cerveza), Dirección General Comercial (FEMSA Cerveza) ${ }^{35}$, Dirección General (CocaCola FEMSA) ${ }^{36}$, Dirección de Finanzas y Desarrollo Corporativo FEMSA ${ }^{37}$.

35 FEMSA Cerveza tiene sus orígenes en 1890 con la Cervecería Cuauhtémoc, en Monterrey, Nuevo León. Posteriormente en 1985 se fusiona con la Cervecería Moctezuma, por lo que cambia su razón social a cervecería Cuauhtémoc Moctezuma, SA de CV. FEMSA Cerveza exporta mundialmente su producto a 63 países (Juárez, mayo 2005: p.36):

36 La relación entre FEMSA y The Coca-Cola Company se ha dado como una sociedad estratégica a largo plazo, que tiene su nacimiento en 1993, al crearse la subsidiaria Coca-Cola FEMSA (Juárez, mayo 2005: p. 36-38)

37 La fuente es de su página: www.femsa.com. 
El interés del ensayo se centra en la subsidiaria o filial de The Coca-Cola Company; es decir, Coca-Cola FEMSA, que se define a sí mismo como una empresa de bebidas (refrescos); sus principales refrescos son: Coca-Cola, Fanta, Sprite, Coca-Cola Light, Lift y Fresca (García, septiembre 2001: p. 38). Coca-Cola FEMSA está constituido además por los productos: latas de bebidas y botellas de vidrio y por el negocio de comercio y logística. En el área de comercio la empresa opera a través de una franquicia: OXXO, la cadena de tiendas de conveniencia más grande de América Latina, en México cuenta con 3400 tiendas que se encuentran estratégicamente ubicadas en las principales áreas metropolitanas del país (Juárez, mayo 2005: p.38).

Asimismo, Coca-Cola FEMSA se consolida en 2003 como el embotellador más grande de México y América Latina al adquirir formalmente la compañía: Panamerican Beverages Inc. (Panamco), con esto amplia su liderazgo y presencia en Latinoamérica, en países como: Guatemala, Nicaragua, Costa Rica, Panamá, Venezuela, Colombia, Brasil y Argentina. ¿Hacia dónde se dirige Coca-Cola FEMSA?, hacia un aumento del volumen de ventas de sus productos a un precio competitivo (penetración de mercado) al tiempo que se mejore su eficiencia operativa. También busca impulsar las habilidades de mercadotecnia de la compañía con el fin de capitalizar oportunidades de mercado ya existentes (desarrollo del mercado), así como desarrollar nuevas ${ }^{38}$ marcas y continuar creando valor de marca de sus bebidas.

Otras preguntas que nos inquietan son ¿cómo es que Coca-Cola FEMSA es la marca de refrescos más importante de América Latina? y ¿cómo es competitiva? $\mathrm{Su}$ ventaja competitiva radica en una estrategia administrativa de liderazgo de costos de operación por su volumen de ventas, además en una estrategia pura particular de innovación: modificación de las bebidas, envases e identidad de marca (The Coca-Cola Company y sus filiales o subsidiarias gastan $\$ 500$ millones de dólares promedio al año en promoción, infraestructura y mercadotecnia). En el caso de Coca-Cola FEMSA en el 2001 impulsó una imagen de identidad a través de 10,000 caminos de distribución en todo el país, así como mediante mayoristas, minoristas, comerciantes con puestos callejeros y tienda OXXO, lo cual efectuó a través de infraestructura como: pintas, refrigeradores, paraguas, mantas

38 Han aparecido nuevas marcas de los productos base (refrescos), pero ahora presentados como refrescos lights (2005), además de refrescos de sabor como Senzao (2001) y agua Ciel mineralizada (2001). 
La estrategia competitiva que adopta la empresa

transnacional en el mercado global

(García, septiembre 2001: 37-41). En el caso de la mercadotecnia y los anuncios o spot en los medios de comunicación, específicamente en México en el 2001, 5 fueron pensados y hechos y producidos en nuestro país, de 30 comerciales que fueron expandidos en el mundo ${ }^{39}$.

En un primer tiempo se puede observar una estrategia pura particular de costos de operación y de innovación en infraestructura y publicidad; en un segundo tiempo, desde un enfoque sistémico, se observa una estrategia de sinergia de ventas (infraestructura, publicidad común y reputación de la marca: Coca-Cola) que da resultados multiplicados para toda la línea de productos Coca-Cola y una sinergia de inversiones (investigación y desarrollo de un producto hacia los demás. (Ansoff, 1976: 100-102).

Por otra parte, tenemos a la empresa transnacional en el sector automovilístico en México y su operación en la producción o manufactura de automóviles. Específicamente, describiremos la forma de operar del complejo flexible de las tres grandes empresas estadounidenses en México: General Motors, Ford y Chrysler. Este complejo flexible proporciona la ventaja competitiva o posición competitiva a estas empresas. Es importante aclarar que este modelo de organización de la empresa transnacional es distinto a los dos modelos de organización multinacional, centralizado y descentralizado anteriormente explicados. Se trata ahora de un modelo alternativo o de un tercer modelo de empresa transnacional; es decir, el modelo de organización global. Su origen es producto de una política global del gobierno mexicano para suplir la estrategia de sustitución de importaciones; tras la crisis de 1982 su organización productiva se basa en los principios de flexibilidad tecnológica, no sólo en la subcontratación de segmentos productivos (maquila). (Ramírez, enero 1997: 29).

39 Esta empresa transnacional (Coca-Cola FEMSA), con un modelo de organización multinacional (Matriz Filiales o UET -Unidades estratégicas de Negocios-), tiene una gestión descentralizada, distinta a Cemex: 1. Mentalidad multinacional: operaciones internacionales tratadas como una cartera de negocios independientes; 2. Federación descentralizada: muchos activos clave, responsabilidades y decisiones descentralizadas; 3. Control personal: relaciones informales entre la central y las filiales, complementadas con simples controles financieros (Bartlett y Ghoshal, 1991:56). 
Adalberto Cabello Chávez

Rafael Reyes Avellaneda

Pedro Solís Pérez

\section{Mapa conceptual (8) \\ Estrategia competitiva: arte de la empresa transnacional Coca-Cola FEMSA}

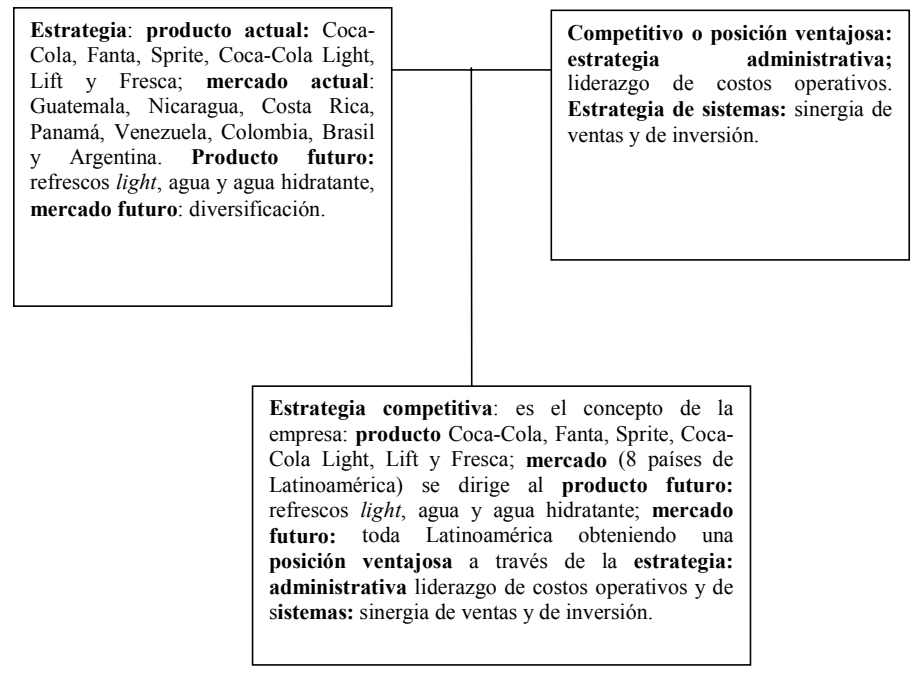

\section{Fuente: Elaboración propia}

Este modelo de organización global ${ }^{40}$ está ejemplificado claramente por la red de proveedores de las empresas automovilísticas estadounidenses (General Motors, Ford y Chrysler) ubicadas en Hermosillo, Chihuahua y Ramos Arizpe. El ensayo en este tercer modelo de la empresa transnacional se centra en el complejo flexible y su funcionamiento como ventaja competitiva para estas tres empresas transnacionales ${ }^{42}$.

40 José Carlos Ramírez S. (enero, 1997: 32) al modelo de organización global lo denomina modelo de complementariedades.

41 Ibid. Este mismo autor menciona otros ejemplos con este tipo de organización global como: 1. Las plantas de motores de Nissan y Renault en Aguascalientes y Gómez Palacio; 2. Las corporaciones estadounidenses de artículos electrónicos en Guadalajara y Tijuana.

42 Hay que aclarar que para fines de este ensayo se piensa que es lo más adecuado, pero por la presentación del mapa conceptual se reconoce que a priori se definirá el concepto de empresa automovilística. 
La estrategia competitiva que adopta la empresa

transnacional en el mercado global

¿Cuáles son los participantes o actores en el modelo de organización global? El núcleo productivo de este modelo organizacional es el complejo flexible o complejo justo a tiempo (JAT) ${ }^{43}$, el cual incluye las operaciones de: "a) maquiladoras y no maquiladoras pertenecientes a las empresas ensambladoras (preferentemente de autos y motores); b) empresas independientes de propiedad estadounidense, japonesa, y, en menor medida, mexicana; c) filiales localizadas en México y en el extranjero, y d) empresas matrices" (Ramírez, enero 1997: 31).

La forma de operar o la base de todas las transacciones de las tres grandes son los llamados centros de consolidación, que no son otra cosa que sitios de aprovisionamiento localizados principalmente en Japón, Estados Unidos, Canadá, Brasil y México. Ahí se acopian las partes producidas regionalmente y se envían a México de acuerdo con un estricto programa de entregas. Las consignaciones se separan en paquetes con el material requerido para un día de producción; cada embarque equivale a los insumos demandados por la ensambladora durante una semana (en Estados Unidos o México) o tres (en los demás casos) (Ramírez, enero 1997: 33).

Los proveedores agrupados en cada centro de consolidación hacen entregas JAT de hojas de acero, componentes de motores, transmisiones, suspensiones y la mayoría de las partes de ensamble al comprador principal designado, al comprador principal designado por la matriz; éste, a su vez, envía a la ensambladora ${ }^{44}$ las partes altamente especializadas con mayor frecuencia, que aquellas que son más estandarizadas generalmente con una semana de anticipación ${ }^{45}$.

43 El principio, ley o máxima del sistema de operación (JAT) se basa en el hecho de que dos actividades son complementarias (dos empresas son complementarias) si la ganancia o valor creado por ambas (empresas) de manera conjunta es mayor que la suma de las ganancias registradas por ellas (empresas) individualmente (Ramírez, enero 1997, p.32). En otras palabras si las empresas trabajan individualmente y cada una obtiene una ganancia de $<2>$, la suma $<2+2=4>$ para que las empresas trabajen en forma conjunta y se complementan la suma debe $\operatorname{ser}<2+2=5>$.

44 En 1997, la planta Ford en Hermosillo producía en promedio 350 autos por turno con cerca de 130 robots, dos veces más que en 1989 y controla 50\% de sus fases de producción con sistemas automatizados (Ramírez, enero 1997: 35).

45 Las tres grandes en México con un modelo de organización global tienen una gestión desconcentrada: 1. Mentalidad global: Roles de Filiales diferenciados y especializados; 2. Competitividad global: activos y recursos dispersos e interdependientes; 3. Aprendizaje mundial: Desarrollo conjunto y coparticipación mundial del conocimiento (Bartlett y Ghoshal, 1991: 74). 
Adalberto Cabello Chávez

Rafael Reyes Avellaneda

Pedro Solís Pérez

\section{Mapa conceptual (9) \\ Estrategia competitiva: arte de las empresas transnacionales: Chevrolet, Ford y Chrysler en México}

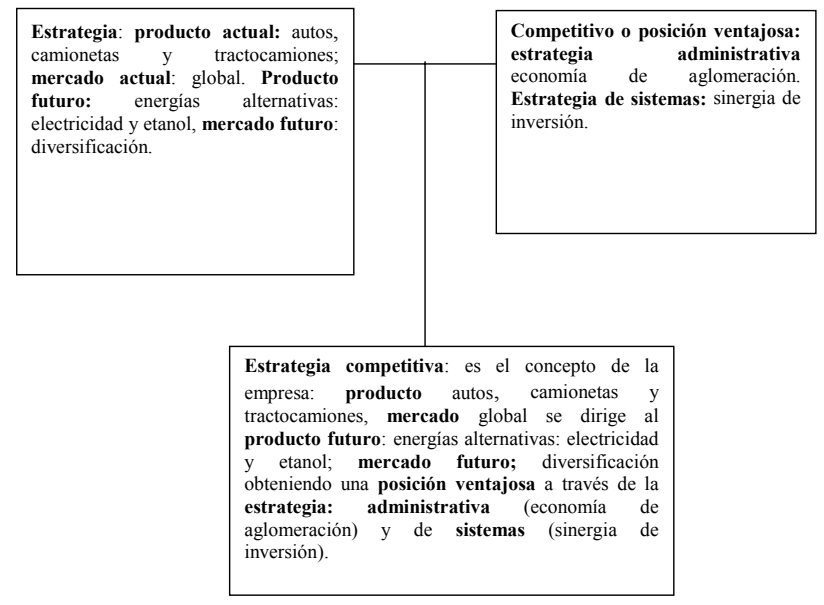

Fuente: Elaboración propia

La ventaja competitiva de las tres grandes no es la economía de escala por sus altos costos para realizar un auto; por una sola planta todo el proceso de manufactura es demasiado costoso para el mercado global. Ahora se trata de una organización laxa, de deseconomías de escala, la estrategia administrativa es de economías de aglomeración; es decir, de economías especializadas donde las empresas disminuyan sus costos en insumos (materia prima, maquinaria, equipo y recursos humanos) y se agrupen entre ellas bajo el principio de sinergia. La estrategia de sistemas es sinergia de inversión de transferencia de investigación y desarrollo entre los cientos o miles de proveedores que participan en el proceso de manufactura.

Las empresas transnacionales mexicanas adoptan e innovan las estrategias propias de las grandes empresas globales, es decir, están a la vanguardia. La sociedad mexicana y otras sociedades de otras latitudes se conectan a sus estrategias de organización (multinacional y global). Tendencia es destino, y el destino del mundo es la tendencia de la empresa transnacional y la concentración del ingreso en sus manos, así como su espiral limitada hacia otros sectores de la economía. El 
La estrategia competitiva que adopta la empresa

transnacional en el mercado global

Estado-nación con características neoliberales debe transformarse en un Estado benefactor para garantizar a través del gasto social niveles de vida mínimos para las clases trabajadoras y los marginados de la sociedad capitalista.

\section{Conclusiones}

1. La aldea global se estructura con nuevas instituciones para su funcionamiento: el Estado regional (neoliberal), la empresa transnacional y el mercado global.

2. La empresa transnacional tiende a dictar el rumbo de la aldea global, lo cual se sustenta en el gran volumen de sus operaciones donde el agente económico es el más activo del mercado.

3. La empresa transnacional frente a la aldea global adopta nuevas prácticas organizacionales que hacen evolucionar las estrategias competitivas de las empresas en el mercado.

4. El análisis del funcionamiento corporativo de algunas de las empresas transnacionales en México permitió identificar las prácticas organizacionales más representativas de este tipo de empresas.

5. Entre las formas que adopta la empresa transnacional se encontraron la organización multinacional y la global.

6. La organización multinacional utiliza la estrategia de reproducir el modelo de filiales en los distintos países del mundo donde se ubica, logrando con ello una gran eficiencia a través del empleo del conocimiento generado en el tratamiento semejante de los problemas estratégicos, tácticos y organizativos que se presentan regularmente en las empresas.

7. La organización global emplea una estrategia de desconcentración de su núcleo de operaciones que le permite aligerar considerablemente sus costos y atenuar en gran medida los conflictos de carácter laboral. Su estrategia competitiva se centra ahora en la logística (just in time) para organizar a infinidad de empresas subcontratadas. 


\section{Bibliografía}

ADLER, Nancy \& Susan Bartholomew (1992) "Managing Globally Competent People", Academy of Management Executive, vol. 6, No. 188\# 3, 52-65.

ANSOFF, H. Igor (1976), La estrategia de la empresa, Ediciones Universidad de Navarra, España.

ARELLANES, Paulino E. (1997), "Economía mundo", en José Luis Orozco y Consuelo Dávila (compiladores), Breviario político de la globalización, Fontamara, México, pp. 82-88.

(1997), "Estrategia global", en José Luis Orozco Consuelo Dávila (compiladores), Breviario político de la globalización, Fontamara, México, pp. 136-144.

BARTLETT, Christopher A. y Sumantra Ghoshal (1991), La empresa sin fronteras: la solución transnacional, Mc Graw Hill-HBS, España.

CABELLO CHÁVEZ, Adalberto y Rafael Reyes Avellaneda (2003), "La red de subcontratación sustentable: categoría organizacional y social para las PyMEs en México, Administración y Organizaciones, año 5, No. 10, julio, pp. 67-76.

CHILD, John (1972), "Organizational Structure, Environment and Performance: The role of Strategic Choise", Sociology, vol. 6, pp. 1-21.

CHUDNOVSKY, Daniel y Andrés López (1999), "Inversión extranjera directa y empresas multinacionales de países en desarrollo. Tendencias y marco conceptual", en Daniel Chudnovsky, Bernardo Kosacoff y Andrés López, Las multinacionales latinoamericanas: sus estrategias en un mundo globalizado, Fondo de Cultura Económica, Buenos Aires.

DOZ, Y. \& C. K. Prahalad (1988), "Quality of Management: An Emerging Source of Global Competition", in N. Hood \& J. Vahlne (eds.) Strategies in Global Competition, Croom Helm, pp. 345-369. 
La estrategia competitiva que adopta la empresa

transnacional en el mercado global

GARCÍA CANCLINI, Nestor (1990), Culturas hibridas: estrategias para entrar y salir de la modernidad, Grijalbo, México.

GARCÍA, María Eugenia (2001), "La vida con Coca-Cola", Expansión, septiembre, año XXXII, No. 823, pp. 32-41.

GEORGANTZAS, N. (1989), "Share in: the missing link of MNC Global Strategy and Structure", Management International Review, 29(3), 19-34.

HERNÁNDEZ, Laura (1997), "Estado", en José Luis Orozco y Consuelo Dávila (compiladores), Breviario político de la globalización, Fontamara, México, pp. 120-124.

HILFERDING, Rudolf(1971), El capital financiero, Edición Revolucionaria, Instituto Cubano del Libro, Cuba.

HOFFMAN, R.C. (1988) "The General Management of Foreign Subsidiaries in the USA: An Exploratory Study", Management International Review, vol. 28.

JUÁREZ, Carlos (2005), "Refrescos, cervezas y botellas", Líderes Mexicanos, Mayo, año 14, tomo 89, pp. 36-38.

KAST, Fremont E. y James E. Rosenzweig (1979), Administración en las organizaciones: un enfoque de sistemas, México, McGraw Hill.

KEEGAN, W. J. (1974), "Multinational scanning: A study of the information sources utilized by headquarters executives in multinational companies", Administrative Science Quarterly, 19, pp. 411-421.

MENDENHALL, M. and G. Oddou (1985) "The dimensions of expatriate acculturation: A review", Academy of Management Review, pp. 39-47.

MINTZBERG, Henry, Bruce Ahlstrand, Joseph Lampel (1999), Safari a la estrategia. Una visita guiada por la jungla del management estratégico, Granica, Argentina. 
MONTAÑO HIROSE, Luis y Marcela Rendón Cobían (1994), "Del zaibatsu al keiretsu. Organización y eficiencia productiva en la gran corporación japonesa", Gestión y política pública, vol. III, No.1, primer semestre, pp. 47-81.

NONAKA, I. \& J. K. Johanson (1985) "Japanese Management: What about the hard skills", Academy of Management Review, vol. 10, No. 188\#2.

(1988) "Toward Middle-Up-Down Management: Accelerating Information Creation", Sloan Management Review, spring.

PNUD (1997), Informe sobre desarrollo humano, Mundi-Prensa, España.

PORTER, Michael E. (1997), Ventaja competitiva: creación y sostenimiento de un desempeño superior, CECSA, México.

(1999), Ser competitivo: nuevas aportaciones y conclusiones, Ediciones Deusto, España.

PRAHALAD, C.K. \& Doz, I. L. (1987), The Multinational Mission: Balancing Local Demands and Global Vision, Free Press, New York.

RAMÍREZ S., José Carlos (1997), "Los modelos de organización de las industrias de exportación en México", Comercio Exterior, vol. 47, No.1, enero, pp. $27-37$.

REYES AVELLANEDA, Rafael (1992), "El Tratado de Libre Comercio: México, Estados Unidos y Canadá", Boletín Cemanahuac, octubre, Espacio Académico.

ROTH, K. (1992) "Implementing International Strategy at the Business Unit Level: The Role of Managerial Decision-Making Characteristics", Journal of Management, 18, pp. 769-789.

SERRANO, Ramón (2005), "Los hombres del cemento", Líderes Mexicanos, año 14 , mayo, tomo 89 , pp. $42-44$. 
La estrategia competitiva que adopta la empresa

transnacional en el mercado global

STEPHEN, R.A. and Yao Apasu (1986) "Exploiting Global Opportunities: A Future Oriented Strategic Perspective For Multinational Corporations", European Management Journal, 4 (1).

SUÁREZ NUÑEZ, Tirso (2001), "La validez de la pequeña empresa como objeto de estudio", mimeo, UAM-I, México.

TAYLOR, W. (1991), "The Logic of Global Business: An Interview with ABB's Percy Barnevik", Harvard Business Review, march-april.

TUNG, R. and E. Miller (1990), "Managing In The Twenty First Century: The Need For Global Orientation", Management International Review, 3(1), pp. 5-18.

TZU, Sun (2003), El arte de la guerra, Gernika, México.

VAN DIJCK, J.J.J. (1990), "Transnational Management in an Evolving European Context", European Management Journal, 8(4), pp. 474-479.

WILLS, St. \& K. Barham (1994), "Being an International Manager", European Management Journal, 12(1), pp. 49-58 .

ZEIRA, Y. and E. Harari (1977), "Genuine multinational staffing policy: Expectations and realities", Academy of Management Journal, 20, pp. 327333.

and M. Banai (1985), "Selection of expatriate managers in MNC's: The host country point of view, International Studies of Management and Organization, pp. 33-51.

ZORRILlA ARENA, Santiago y José Silvestre Méndez (1995), Diccionario de Economía, Limusa, México. (A) 